\title{
Marked Elevations of Serum Creatine Kinase Activity Associated with Antipsychotic Drug Treatment
}

Herbert Y. Meltzer, M.D., Philip A. Cola, M.A., and Mahmoud Parsa, M.D.

Serum creatine kinase (SCK) activity of the skeletal muscle (MM) form is sometimes moderately increased in acutely psychotic patients and may be massively increased as a result of muscle damage. The objective of this study was to characterize the SCK increases in patients treated with novel antipsychotic drugs. SCK activity and myoglobinuria, an index of gross muscle damage, were monitored at varying intervals in schizophrenic or schizoaffective patients treated with antipsychotic drugs. Possible causes of increases in SCK activity, such as trauma, excessive physical activity, exacerbation of psychosis, were assessed. Fifteen instances of massive increases in SCK activity were observed in 11 out of 121 patients (10\%) treated with the following antipsychotic drugs: clozapine, loxapine, haloperidol, melperone, risperidone, or olanzapine. These increases in SCK activity were of the MM type and ranged from 1,206 to 177,363 IU/L (median, 9,600 IU/L). Thus, they were much larger than the increases usually found in acutely psychotic patients or patients with neuroleptic malignant syndrome (range, 500-3,000 IU/L). Only the patient with SCK activity of 177,363 IU/L had rhabdomyolysis as evidenced by myoglobinuria. The onset of the increases was from 5 days to 2 years after initiating treatment, and the increases lasted 4 to 28 days (median, 8 days). Flulike symptoms were present in two of the patients, but the others were asymptomatic. The increases were self-limiting in three cases, despite continuing treatment. Two of three cases rechallenged with the same drug again developed large increases in SCK activity within a week. It is unlikely these increases in SCK activity are related to acute psychosis, trauma, or the neuroleptic malignant syndrome. The increase in SCK activity may reflect the ability of the drugs to increase intermittently cell membrane permeability, especially in skeletal muscle, in some vulnerable subjects. A possible role of serotonin in this process is suggested by the pharmacology of most of the offending drugs. However, in some instances, the increases may have been unrelated to drug treatment. There was no evidence that these increases in SCK activity, despite their magnitude, compromised renal function. Routine monitoring of SCK activity of myoglobinuria during treatment with the antipsychotic drugs studied here is probably not necessary. [Neuropsychopharmacology 15:395-405, 1996]
KEY WORDS: Creatine kinase: Schizophrenia; Clozapine; Risperidone; Serotonin

From the Laboratory of Biological Psychiatry, Department of Psychiatry, Case Western Reserve University School of Medicine, Cleveland, $\mathrm{OH}$.

Address correspondence to: Herbert Y. Meltzer, M.D., Douglas D. Bond Professor of Psychiatry, Department of Psychiatry, University Hospitals of Cleveland, 11100 Euclid Avenue, Cleveland, OH 441065000 .

Received September 13, 1995.
Transient increases in serum creatine kinase (SCK) activity of the skeletal muscle (MM) type of moderate magnitude (2-20 times normal) have been reported in acutely psychotic patients with diagnoses of schizophrenia, mania, and psychotic depression (Bengzon et al. 1966; Meltzer 1968, 1970, 1973a, 1975, 1976a; Taylor and Abichandani 1980; Tsoi et al. 1985). Increased SCK activity may also result from trauma, intramuscular injections, and neuroleptic malignant syndrome (NMS; Meltzer et al. 1970; Meltzer 1973b). Intensive muscular 
activity does not usually produce marked increases in SCK activity (Goode et al. 1977; Meltzer and Moline 1970a; Foster and Kupfer 1973; Goode and Meltzer 1976). Recently, several case reports have noted markedly elevated SCK concentrations in the partial (Parsa et al. 1990) or complete absence of acute psychosis, trauma, or the usual symptoms of NMS (Keshavan et al. 1993; Matcheri et al. 1994; Kirson et al. 1995) in patients treated with clozapine, an atypical antipsychotic drug (Meltzer 1992). Increased SCK levels during acute psychosis is not related to excessive muscle activity and is one manifestation of a variety of types of neuromuscular dysfunction characteristic of psychotic patients, especially those with schizophrenia (Meltzer 1975; Meltzer and Crayton 1974).

Here, we report 11 patients who developed massive increases (the median increase was approximately 50 times the upper limit of normal) in SCK activity, in the complete or nearly complete absence of extrapyramidal symptoms (EPS) or other stigmata of NMS, following treatment with one of six antipsychotic drugs: clozapine, loxapine, melperone, risperidone, olanzapine, and haloperidol. All of these drugs, except haloperidol, have been noted to share a relatively high affinity for the serotonin $5-\mathrm{HT}_{2 \mathrm{~A}}$ receptor compared to their dopamine $\mathrm{D}_{2}$ receptor affinities (Meltzer et al. 1989; Leysen et al. 1988; Christensson 1989; Saller et al. 1990; Moore et al. 1992). The etiology and clinical implications of these increases in SCK activity are discussed.

\section{METHODS}

All patients included in this study were hospitalized. Any patient for whom SCK activity determinations were available during treatment with antipsychotic drugs was included in this study. Diagnoses were established on the basis of a standardized diagnostic interview schedule [the Schedule of Affective Disorders and Schizophrenia (SADS; Endicott and Spitzer 1978), together with all available additional chart review and interview information.

The drugs included in this study were either novel antipsychotic agents for which SCK activity was determined during the course of treatment or loxapine, which was included because it shares a relatively high affinity for the $5-\mathrm{HT}_{2 \mathrm{~A}}$ receptor in vitro and in vivo with these drugs (Meltzer et al. 1989; Leysen et al. 1988; Christensson 1989; Saller et al. 1990; Moore et al. 1992; Stockmeier et al. 1993) and haloperidol.

Case reports, hospital records, and laboratory results from protocol studies were examined for all SCK determinations obtained during the course of treatment. SCK activity was determined in accord with protocol schedules for some patients: melperone, clozapine, olanza- pine, haloperidol, and risperidone. SCK determinations were made by a hospital clinical laboratory or a commercial national laboratory. The normal range of SCK activity as determined by the University Hospitals of Cleveland clinical laboratory is 0 to $225 \mathrm{IU} / \mathrm{L}$ in normal males and 0 to $140 \mathrm{IU} / \mathrm{L}$ in normal females. The intraand interassay coefficients of variation (CV) were $3.5 \%$ and $2.2 \%$, respectively. SCK activity also has been shown to be higher in African Americans than Caucasians (Meltzer and Holy 1974). SCK activity determinations for the olanzapine and haloperidol study subjects were performed by Scicor, Inc. of Indianapolis, Indiana, which provided normal ranges based on race as well as sex and age for schizophrenic patients. The upper limits of normal for SCK activity in that laboratory for Caucasian and African American males is 640 and $1105 \mathrm{IU} / \mathrm{L}$, respectively. The intra- and interassay CV were $3.4 \%$ and $3.3 \%$, respectively. The Scicor lab norms are higher because they include the higher levels expected in African Americans (Meltzer and Holy 1974) and because of differences in the method of determination. Both laboratories reassayed the abnormal values in duplicate or triplicate to ensure that they were not due to laboratory error. For this reason, multiples of the upper limit of normal for each lab should be used to interpret the results reported here. The isoenzyme of CK in serum was determined by electrophoresis. Serum aspartate amino transferase (SGOT), alanine amino transferase, gammaglutamate transferase (SGGT), lactic dehydrogenase $(\mathrm{LDH})$, uric acid, calcium, creatinine and blood urea nitrogen, as well as urine myoglobin, were determined by the clinical laboratories.

\section{RESULTS}

Table 1 provides the number of subjects whose SCK activity was monitored on each of the study drugs, the range and median number of determinations per subject, and the number and percent of patients with at least one determination equal to or higher than $750 \mathrm{IU} / \mathrm{L}$ for University Hospitals of Cleveland or equal to or higher than 3,000 IU/L for Scicor labs. These levels are approximately five times the upper limit of normal and were selected to eliminate from consideration in this report increases in SCK activity that might be related to psychosis or to nonspecific effects, such as physical activity and trauma.

Eleven of the patients had massive increases in SCK activity, with peak values ranging from 1,591 to 177,000 IU/L (median, 9,610 IU/L; see Table 1). The increases ranged from 7.1 to 786 times the upper limit of normal. In most cases, additional samples, either just before or after the peak value, also demonstrated marked increases that were less than the peak levels. Because SCK activ- 
Table 1. Description of Treatment Groups and SCK Increases

\begin{tabular}{|c|c|c|c|c|}
\hline Drug & $\begin{array}{l}\text { Number of } \\
\text { Subjects }\end{array}$ & $\begin{array}{c}\text { Number of } \\
\text { Determinations/Subject }\end{array}$ & $\begin{array}{l}\text { Number of } \\
\text { Marked } \\
\text { Elevations }\end{array}$ & $\begin{array}{l}\text { Patients with } \\
\text { Marked } \\
\text { Elevation (\%) }\end{array}$ \\
\hline Clozapine & 17 & $1-9(3)^{a}$ & 2 & 11.8 \\
\hline Loxapine & 11 & $1-11(4)$ & 3 & 27.3 \\
\hline Melperone & 47 & $1-51(6)$ & 12 & 2.1 \\
\hline Olanzapine/haloperidol & $35^{b}$ & $2-23(8)$ & 4 & 11.4 \\
\hline Risperidone & 11 & $2-8(4)$ & 2 & 18.1 \\
\hline Total & 121 & & $15^{c}$ & 10.0 \\
\hline
\end{tabular}

ity was not monitored daily, these may not have been the actual peak levels. The highest SCK levels were noted between day 5 and approximately 3 months of treatment (median, 14 days). The duration of the increases was 7 to 24 days (median, 9 days).

The patient group included 63 Caucasian males, 28 Caucasian females, 22 African American-males, and 8 African-American females. All were schizophrenic or schizo-affective. Marked increases were found in five Caucasian males, five African-American males, and one African-American female. Males were at greater risk than females (Fisher's Exact, two-tail, $p=.017$ ). However, SCK increases were more frequent in AfricanAmericans than Caucasians (chi-square $=5.74, p=.01$ ). The CK isoenzyme in serum was only the skeletal muscle (MM) form. There were modest increases in SGOT activities (median value was three times normal) at the time of most of the SCK increases. There were no increases in blood urea nitrogen, serum creatinine, uric

Table 2. Peak SCK Activity

\begin{tabular}{llcc}
\hline Patient & \multicolumn{1}{c}{ Drug } & Laboratory & Peak Serum CK (IU/L) \\
\hline 1 & Melperone & $\mathrm{UH}^{a}$ & 11,723 \\
& & & 8,713 \\
2 & Clozapine & $\mathrm{UH}$ & 11,004 \\
3 & Clozapine & $\mathrm{UH}$ & 27,060 \\
4 & Haloperidol & $\mathrm{Sci}^{b}$ & 19,420 \\
& & & 13,200 \\
5 & Olanzapine & $\mathrm{Sci}$ & 15,100 \\
6 & Olanzapine & $\mathrm{Sci}$ & 8,150 \\
& Risperidone & $\mathrm{UH}$ & 1,206 \\
7 & Olanzapine & $\mathrm{Sci}$ & 8,920 \\
8 & Loxapine & $\mathrm{UH}$ & 3,917 \\
& Risperidone & $\mathrm{UH}$ & 1,591 \\
9 & Risperidone & $\mathrm{UH}$ & 9,571 \\
10 & Loxapine & $\mathrm{UH}$ & 177,363 \\
11 & Loxapine & $\mathrm{UH}$ & 5,236 \\
\hline
\end{tabular}

${ }^{a}$ UH, University Hospitals of Cleveland.

${ }^{b}$ Sci, Scicor Laboratories. acid, or calcium in any of the 11 patients at the time of the SCK increases.

The median number of determinations of SCK activity in the other 110 patients with normal or slightly increased SCK levels while on medication was three to eight. They were usually obtained in the first 6 weeks of treatment. Of the 11 patients with massive increases in SCK activity in this study, six had normal SCK levels, and five had elevated SCK levels at admission: 305, 369, $421,3,871$ and 24,640 IU/L. SCK levels were also available at the time of other admissions $(N=23)$ for eight of the patients. SCK levels were higher at admission in three of the eight patients: 659,600, and $914 \mathrm{IU} / \mathrm{L}$ (measured by University Hospitals of Cleveland laboratory) and were within normal limits for the other 20 admissions.

We describe eight of the 11 cases with massive SCK increases. In all cases, known causes of SCK increases such as NMS (e.g., fever, rigidity, autonomic instability), myocardial infarction (EKG, physical signs), infection, trauma, excessive physical activity, and intramuscular injections were sought and not observed, except as noted.

\section{CASE REPORTS}

\section{Case 1 (Melperone)}

EP, a 26-year-old African-American male with chronic paranoid schizophrenia, was admitted to the hospital for a trial of treatment with melperone, an antipsychotic drug that produces low EPSs (Christensson, 1989; Bjerkenstedt 1989; Meltzer et al. 1990). On admission, the patient exhibited delusions of thought broadcasting and thought insertion and reported auditory hallucinations. All admission laboratory tests were within normal limits, with baseline SCK activity of 118 IU/L (normal, $\leqslant 225 \mathrm{IU} / \mathrm{L}$ ). SCK activity during treatment is shown in Figure 1. After obtaining written consent, melperone 
therapy was initiated on day 16 of hospitalization, and a peak dose of $400 \mathrm{mg}$ was reached 10 days later. The patient tolerated the medication well and exhibited a marked decrease in psychotic symptoms over the following 3 weeks. SCK activity was $136 \mathrm{IU} / \mathrm{L}$ on day seven of treatment. On day 35 of hospitalization (day 19 of active treatment with melperone), he developed flulike symptoms with a low-grade fever and mild muscular pain, but no EPS or autonomic dysfunction. SCK activity was 5,661 IU/L. The next day it was 11,723 IU/L. Slight increases in SGOT and SGPT were also present. Urine myoblobin was negative. Melperone was continued for 4 more days, during which time SCK activity decreased to 1,372 IU/L. Melperone was discontinued for 8 days, during which time SCK activity returned to normal. Treatment with melperone was resumed on day 45 of hospitalization, with daily monitoring of SCK activity. SCK activity started to increase 6 days later (520 IU/L). On day 7, SCK activity was 3,216 IU/L, at which time melperone was stopped. The next day, it was $8,713 \mathrm{IU} / \mathrm{L}$ and declined to baseline level 9 days later. Treatment with thioridazine was initiated, without any effect on SCK activity.

\section{Case 2 (Clozapine)}

After several years of unsuccessful trials of various conventional antipsychotics (haloperidol, fluphenazine, thiordazine, loxapine), LV, a 36-year-old Caucasian male, was treated with clozapine. Because of a major motor seizure, phenytoin was added. After 6 months treatment with clozapine (peak dose, $600 \mathrm{mg} /$ day), he became noncompliant and was readmitted to the hospital because of an acute exacerbation of psychosis. Admission blood and urine tests were all normal, except for an SGGT level of $321 \mathrm{IU} / \mathrm{L}$ (normal, 30-135 IU/L) and SCK activity of $421 \mathrm{IU} / \mathrm{L}$. Therapy was reinstituted with cloz- apine and phenytoin. Four weeks after treatment was restarted, SCK activity was found to be 11,004 IU/L (Figure 2), with SGGT activity increased to above 500 IU/L. Clozapine and phenytoin were discontinued. Six days after discontinuing clozapine, SCK activity returned to normal (155 IU/L), but psychotic symptoms worsened. He was restarted on the combination of clozapine (peak dose, $600 \mathrm{mg} /$ day) and phenobarbital. SCK levels and liver enzyme activities remained within normal ranges.

\section{Case 4 (Haloperidol)}

At the time of admission to the hospital for a doubleblind trial of olanzapine versus haloperidol, BE, a 34year-old African-American male, was cognitively intact, but exhibited severe negative symptoms. All laboratory tests were within normal limits, with SCK activity ranged between 167 and $305 \mathrm{IU} / \mathrm{L}$. By the day 6 of double-blind therapy (subsequently known to be haloperidol), SCK activity was found to be $19,420 \mathrm{IU} / \mathrm{L}$. Treatment with haloperidol was stopped. Over the next 7 days, the SCK activity gradually decreased to $747 \mathrm{IU} / \mathrm{L}$, but the patient developed marked positive psychotic symptoms, characterized by formal thought disorder and hallucinatory behavior. Double-blind therapy (haloperidol) was restarted, and once again SCK levels peaked to $13,200 \mathrm{IU} / \mathrm{L}$ by the fifth day of treatment (Figure 3). Drug treatment was discontinued and SCK activity returned to baseline 5 days later. No further increases in SCK activity were noted.

\section{Case 5 (Olanzapine)}

LP, a 42-year-old Caucasian male with a diagnosis of schizoaffective disorder, gave written consent to participate in a double-blind trial of olanzapine versus haloperidol. SCK activity at baseline was 140 IU/L. After 6
Figure 1. SCK levels in a 26-year-old male with schizophrenia treated with melperone. *, Beginning of melperone treatment.

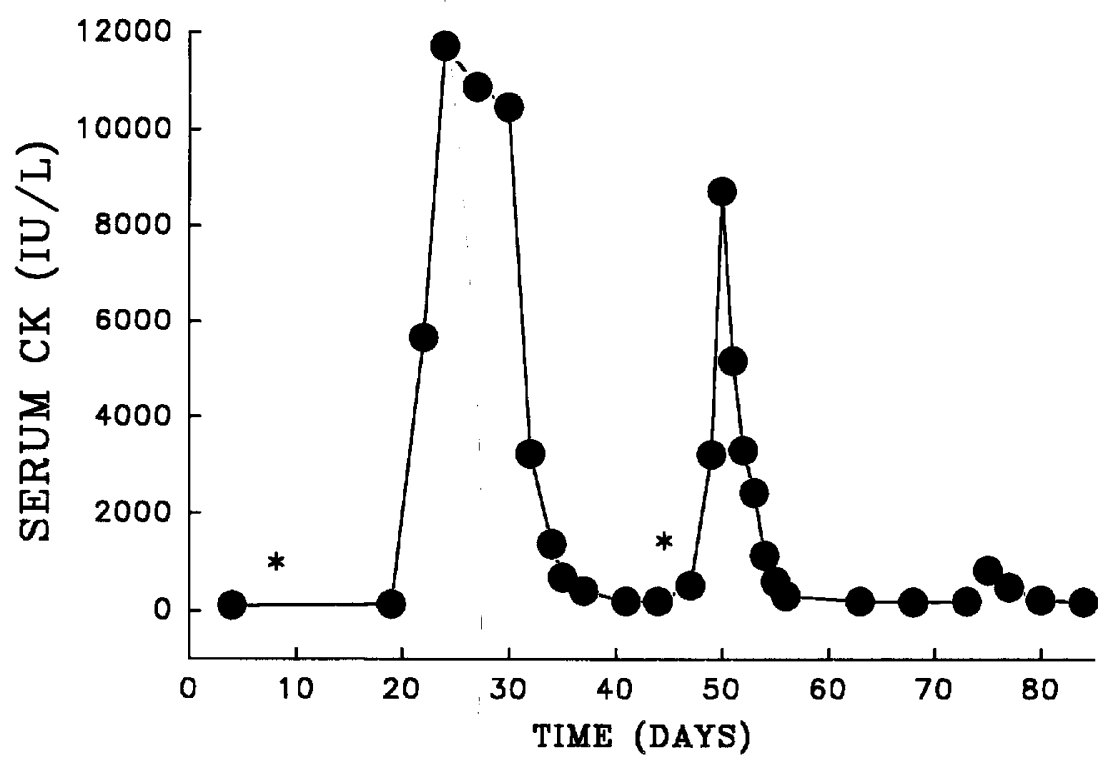




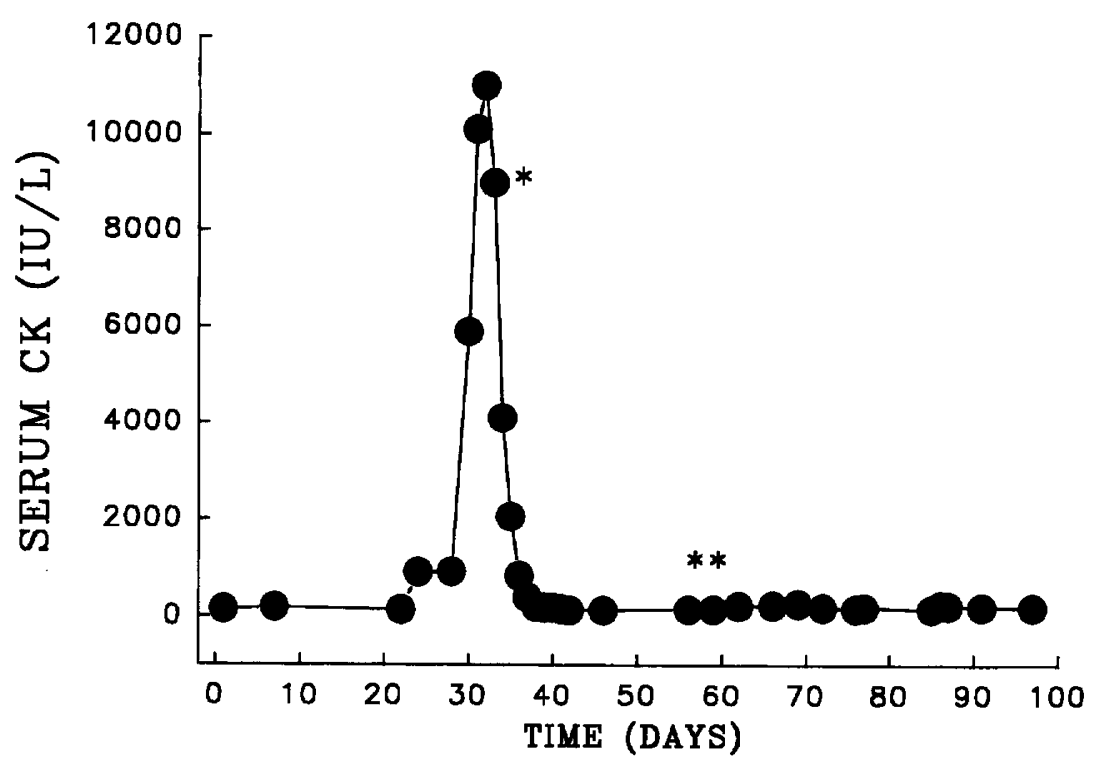

Figure 2. SCK levels in a 36-year-old male with schizophrenia treated with clozapine. ${ }^{*}$, Clozapine discontinued on day 33. ${ }^{* *}$, Clozapine restarted on day 59.

weeks as an outpatient, during which weekly determinations of SCK activity were normal, he was placed on open-label olanzapine because of a lack of response on blinded medication, which was olanzapine. On a dose of $20 \mathrm{mg} /$ day during the fifth week of open treatment, he was found to have a SCK activity of $15,100 \mathrm{IU} / \mathrm{L}$ on a routine outpatient visit (Figure 4). There were no other serum enzyme increases. The patient was no longer psychotic at this time. Olanzapine was discontinued. SCK activity was normal 6 days later. This patient was then started on haloperidol (10 $\mathrm{mg} /$ day) without any further SCK increases in about a 3-month period of observation.

\section{Case 6 (Olanzapine/Risperidone)}

WT, a 33-year-old African-American male with neuroleptic-responsive paranoid schizophrenia, gave written consent to participate in a double-blind study of olanza- pine versus haloperidol. He presented delusions of reference, thought withdrawal, persecutory delusions, and auditory hallucinations at screening and baseline workups. SCK activity at admission was $114 \mathrm{IU} / \mathrm{L}$ and was normal during the 6 weeks of blinded treatment. Because his symptoms did not respond to the blinded (haloperidol) medication, he was then placed on openlabel olanzapine. During the first 5 weeks of open-label olanzapine treatment, SCK activity remained normal and his psychosis improved. On week 6 of open-label olanzapine, during a routine outpatient visit, SCK activity was 8,150 IU/L. Urine screen for cocaine was negative. The patient was discontinued from the protocol, and 3 days later, SCK activity returned to normal. SCK levels were normal on four occasions during the subsequent 4-month period of treatment with thiothixene. In a subsequent trial with risperidone, SCK activity rose

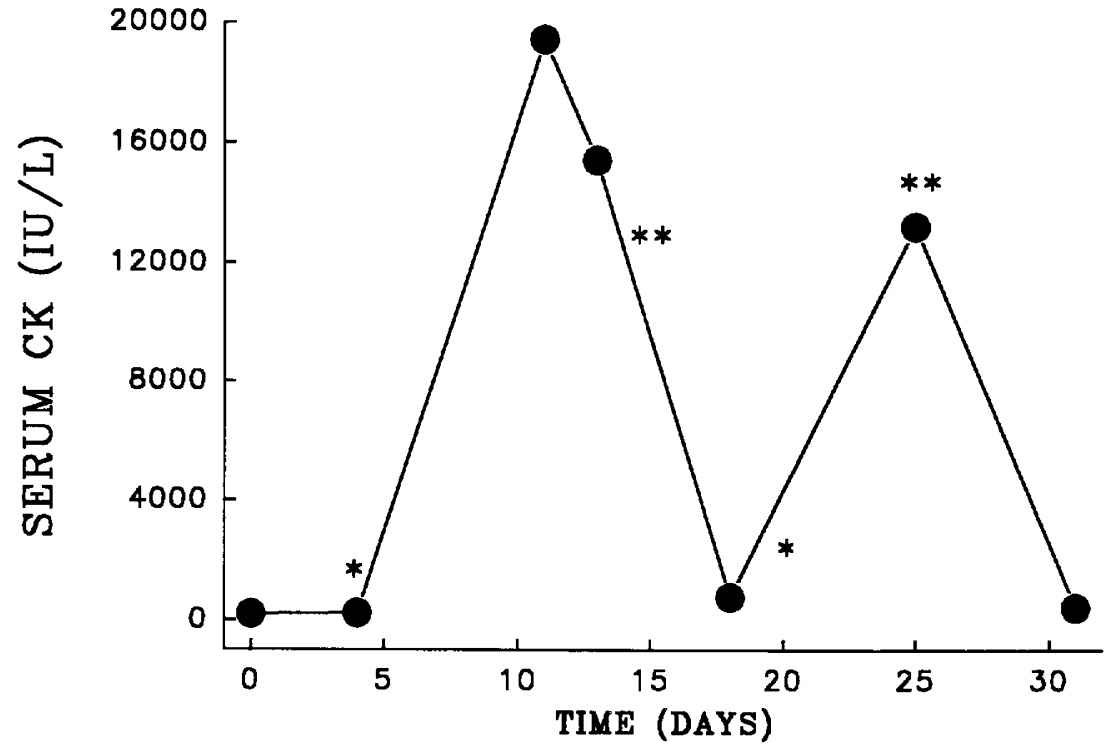

Figure 3. SCK levels in a 34-year-old male with schizophrenia treated with haloperidol. *, Beginning of double-blind treatment. ${ }^{* *}$, Treatment discontinued. 
Figure 4. SCK levels in a 42-year-old male with schizophrenia treated with olanzapine. *, Beginning of double-blind treatment. ${ }^{* *}$, Beginning of open-label olanzapine treatment.

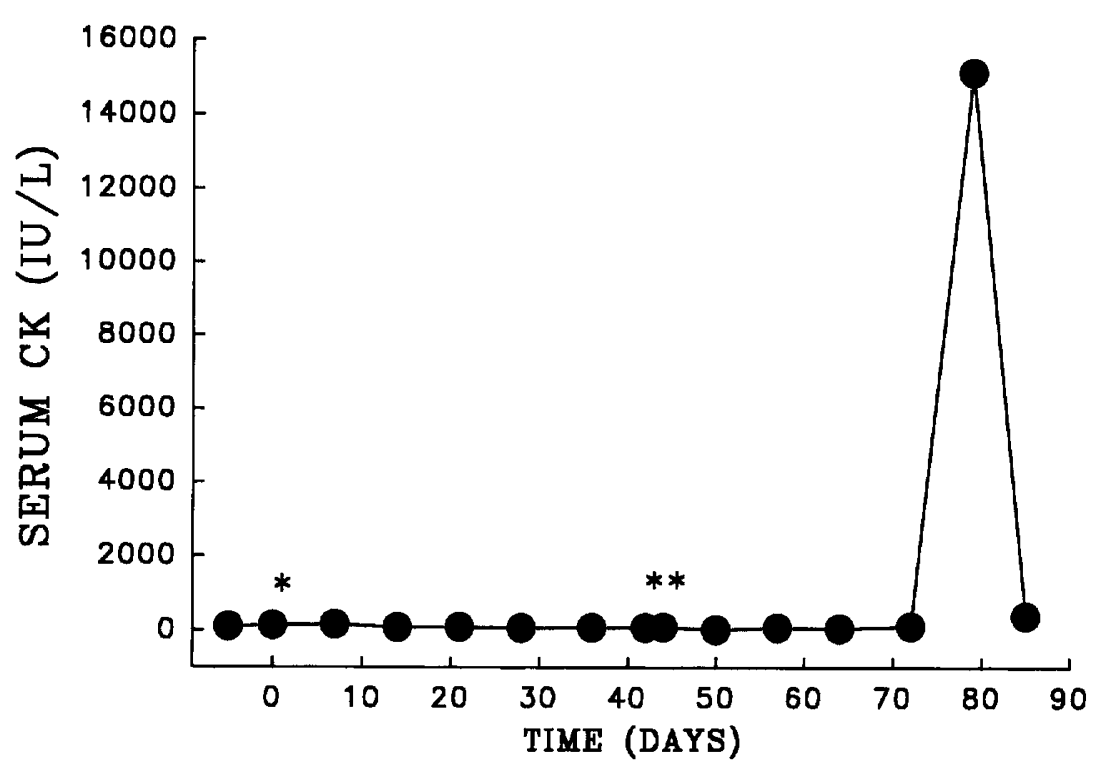

gradually, beginning with the third week of treatment to a peak of $1,206 \mathrm{IU} / \mathrm{L}$ at 4 weeks and then returned to normal over 5 days. No known reason for this increase was noted.

\section{Case 7 (Olanzapine)}

$\mathrm{DH}$, a 21-year-old African-American male diagnosed with chronic undifferentiated schizophrenia, had one psychiatric hospitalization in March of 1994. He was treated with a standard antipsychotic drug and displayed a mild response to treatment without any SCK elevations. He was reevaluated in July 1994 because of persistent symptoms, which included auditory hallucinations, persecutory delusions, and avoidant and antisocial behaviors. He gave written informed consent to begin double-blind therapy with either olanzapine or haloperidol. He was randomized to olanzapine. Screening and baseline SCK activities were 471 and $588 \mathrm{IU} / \mathrm{L}$, respectively. Urine screen for cocaine was negative. After 1 week of blinded therapy, SCK activity increased to $8,920 \mathrm{IU} / \mathrm{L}$. The patient continued double-blind therapy, and within 1 week SCK activity decreased to 970 IU/L (Scicor). Three subsequent SCK activity determinations over the next 3 months were also within normal limits. Four months later, while still receiving olanzapine, SCK activity was found to be $9,610 \mathrm{IU} / \mathrm{L}$. There were no other laboratory abnormalities. SCK levels were 939 IU/L 5 days later. No known cause of increased SCK activity was apparent at the time of both increases in SCK activity.

\section{Case 8 (Loxapine/Risperidone).}

BG, a 30-year-old Caucasian male with treatment-refractory chronic paranoid schizophrenia, was admitted to the hospital for a trial of risperidone. During a previous trial of loxapine, a SCK activity of 3,917 IU/L was noted.
On this admission, the patient exhibited labile affect with ideas of reference and auditory hallucinatons. All the laboratory tests were within normal limits, with a baseline SCK activity of $188 \mathrm{IU} / \mathrm{L}$. After the washout period, treatment was initiated with risperidone at $2 \mathrm{mg}$ / day and increased to $6 \mathrm{mg}$ /day over the next 3 days. Five days later, an elevation in SCK activity (with a peak level of 1,591 IU/L) and a mild increase in SGOT and SGPT were noted. Despite the SCK elevation, the patient was maintained on risperidone at $6 \mathrm{mg} /$ day, and enzyme levels gradually returned to normal range over the following 4 weeks. Multiple SCK determinations were normal during the next 6 months.

\section{Case 10 (Loxapine)}

CL, a 27-year-old African-American female, was admitted to the hospital because of acute "stomach pain" and delusions of being pregnant. Loxapine had been increased to $100 \mathrm{mg} /$ day 3 weeks prior to admission. On physical examination, she was afebrile with blood pressure of $128 / 84 \mathrm{mmHg}$, but with tachypnea (36 respirations per minute), tachycardia ( 130 beats per minute), and moderate substernal tenderness. Blood cell counts were normal. Blood chemistries were significant for SCK activity of $26,100 \mathrm{IU} / \mathrm{L}$, with slight increases in SGOT and LDH values but normal SGPT and SGGT levels. Myoglobin was present in urine, but loxapine was stopped. SCK activity reached 177,000 IU/L (skeletal muscle isoenzyme) over the next 3 days (Figure 5). Despite this, serum creatinine and urea nitrogen values were within normal limits. Electrocardiogram (ECG) showed sinus tachycardia with nonspecific $\mathrm{T}$-wave abnormalities. None of these assessments identified a specific etiology for respiratory distress, abnormal laboratory values, or the elevated SCK levels. A tentative diagnosis of loxapine-induced rhabdomyolysis was made. 


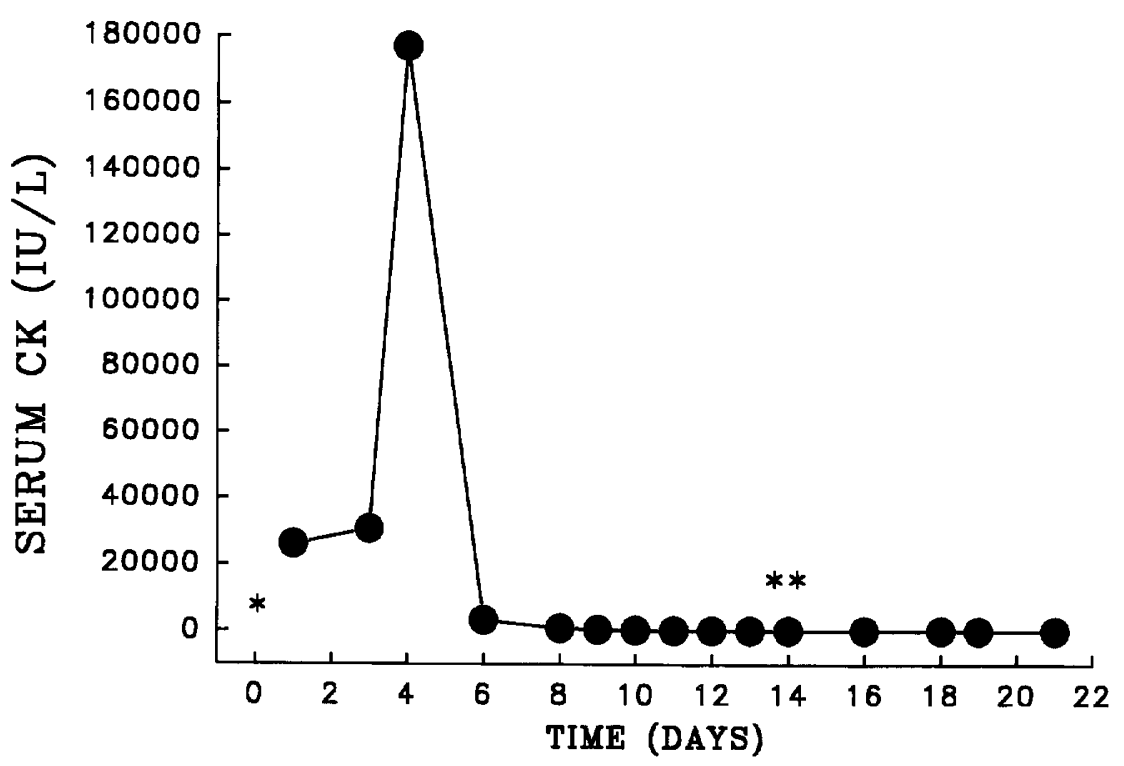

Figure 5. SCK levels in a 27-year-old female with schizophrenia treated with loxapine. *, Loxitane treatment discontinued (100 mg/day), **, Beginning of trilafon treatment.

Supportive treatments and intravenous hydration were initiated. The syndrome resolved within 10 days of stopping loxapine. All the blood chemistries, including liver enzymes and SCK activity, returned to normal ranges. She was started on perphenazine with a peak dose of $24 \mathrm{mg} /$ day. No increases in SCK activity ensued.

\section{DISCUSSION}

We report here 11 cases of very marked increases in SCK activity in patients with schizophrenia treated with a variety of antipsychotic drugs. SCK increases began during treatment with antipsychotic drugs in all cases. The increases in SCK activity were of the skeletal muscle type. There was no evidence that muscle trauma or hyperactivity contributed to the release of CK from skeletal muscle in any of these cases. The time after initiation of antipsychotic treatment when increases in SCK activity were first detected ranged from 5 days to 2 years, but may have been present even earlier in some cases, as SCK activity was monitored intermittently. A weekly monitoring schedule would have been the minimum necessary to detect most increases, based on the observed duration of increases of 4 to 28 days (median, 9 days). Seven of the increases were detected as part of research protocols that called for routine SCK determinations. One increase was detected at admission, one during a routine check, two because of a flulike syndrome, and one during an acute exacerbation of psychosis as clozapine was being tapered. One patient had two marked increases on two different drugs. The frequency of monitoring in the other 110 cases was sparse, so it is not possible to rule out asyptomatic, transient $\mathrm{SCK}$ increases in these patients.
The increases in SCK activity noted here were much greater in magnitude and longer in duration than previously reported in acutely psychotic patients, which usually ranged from 2 to 20 times the upper limit of normal (Meltzer 1968, 1969, 1970, 1971, 1975, 1976a; Meltzer and Moline 1970b). Peak levels in the patients studied here ranged from 1,591 to 177,363 IU/L (median, 11,004 IU/L). The median increases were approximately 100 times the levels in these subjects at baseline or after recovery. The duration of the increases in the cases reported here once medication was stopped ranged from 4 to 28 days (median, 9 days), which is significantly longer than the 2- to 5-day duration of elevated SCK activity usually present during acute psychosis (Meltzer $1968,1969,1970,1976 a)$. To our knowledge, these increases were not associated with any loss of muscle function, such as weakness, because the amount of CK activity in skeletal muscle is enormously greater than the amount that would have been necessary to produce the increase noted here. In addition, other means of highenergy phosphate metabolism may have been used to compensate for the loss of CK activity.

Increases in SCK activity were first reported to occur in NMS during the course of earlier studies of SCK activity in schizophrenia by this laboratory (Meltzer 1973b). More recently, Gurrera and Romero (1993) reported SCK levels in 65 probable cases of NMS. The median increase was $800 \mathrm{IU} / \mathrm{L}$. Only 5/65 (7.7\%) cases had serum levels equal to or higher than $5,000 \mathrm{IU} / \mathrm{L}$, with a peak of $30,000 \mathrm{IU} / \mathrm{L}$. Occasional cases of NMS have extremely high SCK activity (e.g., 220,000 IU/L; Hashimoto et al. 1984). However, none of the major features of NMS, such as muscular rigidity, autonomic instability, or fever, were noted in the patients reported here, with the possible exception of Case 10. SCK increases in published cases of clozapine-related NMS have not been as 
high as the levels reported here (Pearlman 1986; Kellam 1987; Pope et al. 1986; Das Gupta and Young 1991; Miller et al. 1991; Thornberg and Ereshefsky 1993). There have been several case reports of increased SCK activity in clozapine-treated patients that have been ascribed to NMS without muscular rigidity (Nomopolous et al. 1990; Goates and Escobar 1992). Neither of these cases were comparable to the cases reported here. Increased SCK activity has been reported in association with neuroleptic-induced acute dystonia (Lui 1979; Cavanaugh and Finlayson 1984), as well as severe or even mild-tomoderate tardive dyskinesia (Egan et al. 1993). Increased SCK activity during neuroleptic withdrawal also has been reported by Malas and van Kammen (1982). This is not relevant to any of the cases reported here, except for Case 3, who developed a large increase in SCK activity as clozapine was being withdrawn. Neither acute dystonia nor severe tardive dyskinesia were present in any of the patients reported here.

Cocaine overdosage has been reported to be associated with rhabdomyolysis and high SCK activity (e.g., 5,670 IU/L; Pagala et al. 1993). Patients 6, 7, and 11 had abused cocaine prior to admission but had normal SCK activities at admission and no evidence of cocaine in urine samples. Phencyclidine (PCP) may occasionally cause rhabdomyolysis in man (Merigian and Roberts 1987), as may amphetamine (Grossman et al. 1974). Rhabdomyolysis has been reported with amphetamine (Grossman et al. 1974; Terada et al. 1988; Watson et al. 1993), 3-4methylenedioxymethylamphetamine ("Ecstasy"; Henry et al. 1992; Forrest et al. 1994), 3,4-methylenedioxyethamphetamine ("Eve"; Tehan et al. 1993), and pemoline, an indirectly acting sympathomimetic with actions similar to those of amphetamine (Briscoe et al. 1988). In the latter case, this was associated with prolonged coma. There was no evidence of PCP, amphetamine, or substituted amphetamine abuse in any of the cases we report.

The true incidence of SCK increases in this population cannot be ascertained because SCK levels were not routinely checked during the course of hospitalization. There were no SCK data available in the majority of the patients treated with clozapine at this center. However, SCK activity was studied five times a week in 318 hospitalized schizophrenic and other psychiatric patients (median duration of hospitalization, 34 days) treated mainly with haloperidol, chlorpromazine, thioridazine, or fluphenazine. Close attention was paid to adventitious causes of SCK increases (Meltzer 1968, 1969, 1970, 1976a; Cogen et al. 1978). SCK levels of the magnitude we note were completely absent in all of these patients (upper limit of normal, $100 \mathrm{IU} / \mathrm{L}$, depending on race and sex). Thus, the assay used in our previous studies is comparable to that used at University Hospitals of Cleveland but would have produced lower results (by $50 \%$ to $75 \%$ ) than those obtained by the commercial laboratory used in the clinical trials.
Several other cases of large increase in SCK levels in an otherwise unremarkable clozapine-treated patients have also been reported. Keshavan et al. (1993) described a patient with a maximum SCK activity of $6,520 \mathrm{IU} / \mathrm{L}$ and marked increase in liver enzymes after 3 weeks of treatment. This patient also had increased SCK elevations 1 week after a second trial of clozapine, as well as marked increases in levels of liver enzymes. Matcheri et al. (1994) and Kirson et al. (1995) reported clozapinetreated patients with SCK activity of $6,520 \mathrm{IU} / \mathrm{L}$, and 34,630 and 47,195 IU/L, respectively. Both patients reported by Kirson et al. (1995) had elevated serum liver enzymes without evidence of NMS. A case of clozapineinduced increase in liver enzymes that did not recur after rechallenge with clozapine has been described (Meltzer et al. 1980).

It is noteworthy that on rechallenge with the same drugs, two (Cases 1 and 4, but not Case 2) of three cases studied here also showed a prompt recurrence of increased SCK activity of similar magnitude and time course. However, three patients (Cases 7, 8, and 9), showed gradual decreases in SCK activity to normal levels despite continued treatment with olanzapine or risperidone. None of the other four patients with large increases in SCK activity during treatment developed high SCK when shifted to thioridazine, haloperidol, or perphenazine.

The SCK and liver enzyme elevations we noted were most likely related to drug treatment, especially because of the two cases (Cases 1 and 4) in which rechallenging with the same drug raised SCK levels within 1 week. On the other hand, one case (Case 2) showed no recurrence in elevations of SCK activity when rechallenged, and two cases showed a return of SCK activity to normal despite continued risperidone treatment. In one of these, a second increase occurred, then again levels returned to normal. These data suggest that at least two different mechanisms may be present or that a state-dependent vulnerability may be relevant to the pathophysiology of a single process. The self-limiting nature of the SCK increases in three cases indicates that state-dependent vulnerability factors or exogenous factors not yet identified may be of importance. This statedependent factor may explain why SCK increases were not observed during prior exposure to the drugs implicated here in patients 2, 8, and 9. Except for Case 2, in which the CK increase occurred while the patient was receiving clozapine and phenytoin, the patients received only the antipsychotic indicated. The highest SCK levels were noted in a patient with a flulike syndrome (Case 10), which did not appear to be NMS, but the other patient with infectious symptoms (Case 1) did not noticeably differ from the other nine patients in the magnitude of the increase in SCK activity.

The very large increases in SCK activity reported appear to be less frequent in patients treated with typical 
neuroleptic drugs (Meltzer 1975; Meltzer et al. 1980). However, smaller elevations in SCK activity due to neuroleptic treatment have been reported (Pearlman et al. 1988). Molindone has been reported to produce rhabdomyolysis (Johnson et al. 1986). A case of thiothixeneinduced severe dystonia leading to rhabdomyolysis has been reported (Ravi et al. 1982). It may be relevant that the five of the six drugs definitely associated with SCK increases in this study are relatively potent $5-\mathrm{HT}_{2 \mathrm{~A}}$ antagonists compared to their $\mathrm{D}_{2}$ receptor potency (Meltzer et al. 1989). Absolute $5-\mathrm{HT}_{2}$ receptor potency as measured in vitro is not a distinguishing feature of these six drugs because melperone is weaker than chlorpromazine in this regard. However, chlorpromazine is a more potent $\mathrm{D}_{2}$ receptor antagonist than a $5-\mathrm{HT}_{2}$ receptor antagonist (Meltzer et al. 1989).

A high-affinity $5-\mathrm{HT}$ receptor $\left(K_{\mathrm{d}} 1.46 \mathrm{nM}\right)$ in the sarcolemma has been identified using ${ }^{125}$ iodolysergic acid diethylamide (Moretti-Rojas et al. 1983). This is unlikely to be a $5-\mathrm{HT}_{2 \mathrm{~A}}$ or $5-\mathrm{HT}_{2 \mathrm{C}}$ binding site because of the reported pattern of affinities for $5-\mathrm{HT}_{2}$ antagonists, but it could be another type of 5-HT receptor.

Serotonin has been reported to accumulate in skeletal muscle by passive diffusion (Stahl and Meltzer 1977). We (Meltzer 1976b) and others (Narukami et al. 1991) have demonstrated that 5-HT can be toxic to skeletal muscle, leading to necrosis and massive increases in SCK activity in rodents. In particular, some tricyclic drugs, such as imipramine, have been found to potentiate the toxic effects of 5-HT on rat skeletal muscle (Meltzer 1976b). Thus, the antipsychotic drugs studied here, all of which are tricyclics, might have interacted with endogenous 5-HT to cause some skeletal muscle injury. The absence of myoglobinuria in all but one case suggests that gross injury to skeletal muscle is absent in most cases. $5-\mathrm{HT}_{2}$ receptors have been shown to exert a potent, tonic influence on blood flow in rat skeletal muscle that can be blocked by $5-\mathrm{HT}_{2}$ antagonists (Verheyen et al. 1984; Ramage 1988). It is also noteworthy that the 5- $\mathrm{HT}_{2 \mathrm{~A} / 2 \mathrm{C}}$ agonist 1-(2,5-dimethoxy-4-iodophenyl)-2-aminopropane (DOI) can cause malignant hyperthermia (MH) in pigs (Löscher et al. 1993). Malignant hyperthermia is characterized by generalized skeletal muscle rigidity, increased SCK activity, and hyperthermia and may be related to NMS (Meltzer 1973b). However, as stated, there was no evidence to suggest subclinical NMS in any of the cases reported here. Moreover, because $5-\mathrm{HT}_{2}$ antagonists block the ability of DOI to induce MH in pigs (Löscher et al. 1990), we would have expected the antipsychotic drugs studied here to inhibit any endogenous process related to $5-\mathrm{HT}_{2 \mathrm{~A}}$ receptor stimulation that might lead to an NMS-like process, unless these drugs were partial agonists.

It is noteworthy that a large group of growth factors necessary for the maintenance of motor neurons and, indirectly, muscle fibers have been identified, such as brain-derived neurotrophic factor, neurotrophin-3, neurotrophin $4 / 5$, ciliary neurotrophic factor, transforming growth factor $\beta$, fibroblast growth factor, and plateletderived growth factor (Yuen and Mobley 1995). The possibility that the antipsychotic drugs cause alterations in the relationships between these growth factors, motor neurons, and muscle fibers is an intriguing possible explanation of the results reported here.

The marked elevations in SCK activity noted could be potentially toxic to kidney function (Coryell et al. 1978) if accompanied by increased uric acid and myoglobin. Fortunately, no increases in these substances were observed in any of these cases. SCK increases in 15 cases of nontraumatic rhabdomyolysis and acute renal failure were comparable to those observed here (range, 11.5-120,00 IU/L; median, 9,250 IU/L; Grossman et al. 1974). The cause of renal failure in these cases has been suggested to be rapid entry of preformed intracellular creatinine into the extracellular fluid through damaged muscle-cell membranes (Grossman et al. 1974). Similarly, the hyperkalemia and hypo- or hypercalcemia seen in rhabdomyolysis and renal failure were not observed here. These differences suggest a selective increase in sarcolemma permeability rather than muscle necrosis as a cause of the increased SCK activity reported. It is, therefore, likely that any SCK elevations, such as those reported, if they do develop during the course of treatment with clozapine, are usually not accompanied by skeletal muscle necrosis are are usually self-limiting. A comprehensive study of a consecutive series of cases is indicated, however, to determine the true incidence of these elevations and whether they are ever associated with such conditions as hyperuricemia, hyperkalemia, myoglobinuria. Based on the data we report, the incidence of large increases in SCK levels during treatment with clozapine and related antipsychotic drugs may be as high as $1 \%$ to $10 \%$, but the timing of the increases may be highly variable.

In conclusion, markedly increased SCK levels were observed in approximately $10 \%$ of patients treated with clozapine, risperidone, melperone, olanzapine, haloperi$\mathrm{dol}$, and loxapine. These increases were self-limiting in some cases. The basis or the increase in SCK activity may be increased cell-membrane permeability. These increases do not appear to be related to NMS. It may be safe to rechallenge patients who develop large SCK increases on these drugs shortly after the observed increases have subsided. The risk of renal damage in association with the SCK increases appears minimal.

\section{ACKNOWLEDGMENT}

The research reported was supported in part by USPHS grant \# MH 41684, GCRC grant \# MO1RR00080, the National Alliance for Research on Schizophrenia and Depression (NAR- 
SAD), as well as grants from the Elisabeth Severance Prentiss and John Pascal Sawyer foundations and Stanley Foundation. HYM is the recipient of a USPHS Research Career Scientist Award (\# MH 47808). The secretarial assistance of Ms. Lee Mason is greatly appreciated.

\section{REFERENCES}

Bengzon A, Hippius H, Kanig K (1966): Some changes in the serum during treatment with psychotropic drugs. J Nerv Ment Dis 143:369-376

Bjerkenstedt L (1989): Melperone in the treatment of schizophrenia. Acta Psychiatr Scand 352(Suppl):35-39

Briscoe JG, Curry SC, Gerkin RD, Ruiz RR (1988): Pemolineinduced choreoathetosis and rhabdomyolysis. Med Toxicol Adverse Drug Exp 3:72-76

Cavanaugh JJ, Finlayson RE (1984): Rhabdomyolysis due to acute dystonic reaction to antipsychotic drugs. Clin Psychiatry 45:356-357

Christensson EG (1989): Pharmacological data of the atypical neuroleptic compound melperone (Buronil $\left.{ }^{\circledR}\right)$. Acta Psychiatr Scand 352(Suppl):7-15

Cogen FK, Rigg G, Simmons JL, Domino EF (1978): Phencyclidine-associated acute rhabdomyolysis. Ann Intern Med 88:210-212

Coryell W, Norby LH, Cohen LH (1978): Psychosis-induced rhabdomyolysis. Lancet 2:381-382

Das Gupta K, Young A (1991): Clozapine-induced neuroleptic malignant syndrome. J Clin Psychiatry 52:105-107

Egan MF, Abi-Dargham A, Kirch DG, Wyatt RJ (1993): Serum creatine phosphokinase elevations in patients with tardive dyskinesia. Brit J Psychiatry 162:551-553

Endicott J, Spitzer RL (1978): A diagnostic interview: The schedule for affective disorders and schizophrenia. Arch Gen Psychiatry 35:837-844

Forrest AR, Galloway JH, March ID, Strachan GA, Clark JC (1994): A fatal overdose with 3,4-methylenedioxyamphetamine derivates. Forensic Sci Int 64:57-59

Foster FG, Kupfer DJ (1973); Psychomotor activity and serum creatine phosphokinase activity. Arch Gen Psychiatry 29:752-758

Goates MG, Escobar JI (1992): An apparent neuroleptic malignant syndrome without extrapyramidal symptoms upon initiation of clozapine therapy: Report of a case and results of a clozapine rechallenge. J Clin Psychopharmacol 12:139-140

Goode DJ, Meltzer HY (1976): Effects of isometric exercise on serum creatine phosphokinase activity. Arch Gen Psychiatry 33:1207-1211

Goode DJ, Weinberg DH, Mazura TA, Curtis G, Moretti RJ, Meltzer HY (1977): Effect of limb restraints on serum creatine phosphokinase activity in normal volunteers. Biol Psychiatry 12:743-755

Grossman RA, Hamilton RW, Morse BM, Penn AS, Goldberg M (1974): Nontraumatic rhabdomyolysis and acute renal failure. N Eng J Med 291:807-811

Gurrera RJ, Romero JA (1993): Enzyme elevation in the neuroleptic malignant syndrome. Biol Psychiatry 34:634-640
Hashimoto F, Sherman CB, Jeffery WH (1984): Neuroleptic malignant syndrome and dopaminergic blockade. Arch Intern Med 144:629-630

Henry JA, Jeffreys KJ, Dawling S (1992): Toxicity and deaths from 3,4-methylenedixoymethamphetamine ("ecstasy"). Lancet 340:384-387

Johnson SB, Alvariz WA, Freinhar JP (1986): A case of massive rhabdomyolysis following molindone administration. J Clin Psychiatry 47:607-608

Kellam AMP (1987): The neuroleptic-malignant syndrome, so-called: A Survey of the world literature. Brit J Psychiatry 150:752-759

Keshavan MS, Stecker J, Kambhapatio RK (1993): Creatine kinase elevations with clozapine. Brit J Psychiatry 64:118 120

Kirson JI, McQuistion HL, Pierce DW (1995): Severe elevations in serum creatine kinase associated with clozapine. J Clin Psychopharmacol 15:287-288

Leysen JE, Gommeren W, Eens A, de Chaffoy de Courcelles D, Stoof JC, Janssen PAJ (1988): Biochemical profile of risperidone, a new antipsychotic. J Pharmacol Exp Ther 247:661-670

Löscher W, Witte U, Fredow G, Ganter M, Bickhardt K (1993): Pharmacodynamic effects of serotonin (5-HT) receptor ligands in pigs: Stimulation of $5-\mathrm{HT}_{2}$ receptors induces malignant hyperthermia. Naunyn-Schmiedeberg's Arch Pharmacol 341:483-493

Lui WY (1979): Phenothiazine-induced dystonia associated with an increase in serum creatine phosphokinase. Archives of Disease in Childhood 54:150-151

Malas KL, van Kammen DP (1982): Markedly elevated creatine phosphokinase levels after neuroleptic withdrawal. Am J Psych 139:231-232

Matcheri S, Stecker J, Kambhampati K (1994): Creatine kinase elevations with clozapine. Brit J Psychiatry 164:118-120

Meltzer HY (1968): Creatine kinase and aldolase in serum: Abnormality common to acute psychoses. Science 159: $1368-1370$

Meltzer HY (1969): Muscle enzyme release in the acute psychoses. Arch Gen Psychiatry 21:102-112

Meltzer HY (1970): Increased activity of creatine phosphokinase and aldolase in the acute psychoses: Case reports. J Psychiatr Res 7:249-262

Meltzer HY (1971): Plasma creatine phosphokinase activity, hypothermia and stress. Am J Physiol 221:896-901

Meltzer HY (1973a): Creatine phosphokinase activity and clinical symptomatology: A study in acute schizophrenic patients. Arch Gen Psychiatry 29:589-593

Meltzer HY (1973b): Rigidity, hyperpyrexia and coma following fluphenazine enanthate. Psychopharmacologia (Berlin) 29:337-346

Meltzer HY (1975): Neuromuscular abnormalities in the major mental illnesses. I. Serum enzyme studies. In Freedman DX (ed), Biology of the Major Psychoses. Research Publications Association of the Research in Nervous Mental Disorders, vol. 54. New York: Raven Press, pp 165-188

Meltzer HY (1976a): Neuromuscular dysfunction in schizophrenia. Schizophr Bull 2:106-135 
Meltzer HY (1976b): Skeletal muscle necrosis following membrane-activity drugs plus serotonin. J Neurol Sci 28:41-56

Meltzer HY (1992): Treatment of the neuroleptic non-responsive schizophrenic patients. Schizophr Bull 18:515-542

Meltzer HY, Crayton JW (1974): Muscle abnormalities in psychotic patients. II. Serum CPK activity, fiber abnormalities and branching and sprouting of subterminal nerves. Biol Psychiatry 8:191-208

Meltzer HY, Holy PA (1974): Black-white differences in serum creatine phosphokinase (CPK) activity. Clin Chim Acta 54:215-224

Meltzer HY, Moline R (1970a): Plasma enzymatic activity after exercise. Study of psychiatric patients and their relatives. Arch Gen Psychiatry 22:390-397

Meltzer HY, Moline R (1970b): Muscle abnormalities in acute psychoses. Arch Gen Psychiatry 23:481-491

Meltzer HY, Mrozak S, Boyer M (1970): Effects of intramuscular injections on serum creatine phosphokinase activity. Am J Med Sci 259:42-48

Meltzer HY, Ross-Stanton J, Schlessinger S (1980): Mean serum creatine kinase activity in patients with functional psychoses. Arch Gen Psychiatry 37:650-655

Meltzer HY, Matsubara S, Lee J-C (1989): Classification of typical and atypical antipsychotic drugs on the basis of dopamine $\mathrm{D}_{1}, \mathrm{D}_{2}$ and serotonin $2 \mathrm{p} K_{i}$ values. J Pharmacol Exp Ther 251:238-246

Meltzer HY, Alphs LD, Bastini B, Ramirez L (1990): Effect of melperone in treatment-resistant schizophrenia. In Stefanis CN, Soldatos CR, Rabavilas AD (eds), Psychiatry Today, Accomplishments and Promises, VIII World Congress of Psychiatry Abstracts. New York: Excerpta Medica International Congress Series 899, p 502

Merigian KS, Roberts JR (1987): Cocaine intoxication: Hyperpyrexia, rhabdomyolysis and acute renal failure. J Toxiol Clin Toxicol 25:135-148

Miller DD, Sharafuddin MJA, Kathol RG (1991): A case of clozapine-induced neuroleptic malignant syndrome. J Clin Psychiatry 52:99-101

Moore NA, Tye NC, Axton MS, Risius FC (1992): The behavioral pharmacology of olanzapine, a novel "atypical" antipsychotic agent. J Pharmacol Exp Ther 262:545-551

Moretti-Rojas I, Ezrailson EG, Birnbaumer L, Entman ML, Garber AJ (1983): Serotonergic and adrenergic regulation of skeletal muscle metabolism in the rat. II. The use of $\left.{ }^{125}\right]$ iodolysergic acid diethylamide and $\left[{ }^{125}\right]$ iodopindolol as probes of sarcolemmal receptor function and specificity. J Biol Chem 258:12499-12508

Narukami H, Yoshioka K, Zhao J, Miike T (1991): Experimental serotonin myopathy as an animal model of muscle degeneration and regeneration in muscular dystrophy. Acta Neuropathol Berlin 81:510-516

Nomopolous P, Flaum M, Miller DD (1990): Atypical neuroleptic malignant syndrome (NMS) with an atypical neuroleptic: Clozapine-induced NMS without rigidity. Ann Clin Psychiatry 2:251-253

Pagala M, Amaladevi B, Azad D, Pagala S, Herzlich B, Namba T, Grob D (1993): Effect of cocaine on leakage of creatine kinase from isolated fast and slow muscles of rat. Life Sci 52:751-756
Parsa MA, Rohr T, Ramirez LF, Meltzer HY (1990): Neuroleptic malignant syndrome without neuroleptics. J Clin Psychopharmacol 10:437-438

Pearlman CA (1986): Neuroleptic-malignant syndrome: A review of the literature. J Clin Psychopharmacol 6:257273

Pearlman CA, Wheadon P, Epstein S (1981): Creatine kinase elevation after neuroleptic treatment. Am J Psychiatry 145:1018-1019

Pope HG, Keck PE, McElroy SL (1986): Frequency and presentation of neuroleptic malignant syndrome in a large psychiatric hospital. Am J Psychiatry 143:1227-1233

Ramage AG (1988): Examination of the effects of some $5-\mathrm{HT}_{2}$ receptor antagonists on central sympathetic outflow and blood pressure in anaesthetised cats. Naunyn-Schmiedeberg's Arch Pharmacol 338:601-607

Ravi SD, Borge GF, Roach FL (1982): Neuroleptics, laryngealpharyngeal dystonia, and acute renal failure. J Clin Psychiatry $43: 300$

Saller CF, Czupryna MJ, Salama AL (1990): 5- $\mathrm{HT}_{2}$ receptor blockade by ICI 169,369 and other $5-\mathrm{HT}_{2}$ antagonists modulates the effects of $\mathrm{D}_{2}$ dopamine receptor blockade. J Pharmacol Exp Ther 253:1162-1170

Stahl SM, Meltzer HY (1977): Serotonin accumulation by skeletal muscle. Exp Neurol 54:42-53

Stockmeier CA, DiCarlo JJ, Zhang Y, Thompson P, Meltzer HY (1993): Characterization of typical and atypical antipsychotic drugs based on in vivo occupancy of serotonin 2 and dopamine 2 receptors. J Pharmacol Exp Ther 266: 1374-1384

Taylor JR, Abichandani L (1980): Creatine phosphokinase elevations and psychiatric symptomatology. Biol Psychiatry 15:865-780

Tehan B, Hardern R, Bodenham A (1993): Hyperthermia associated with 3,4-methylenedioxy-ethamphetamine ("Eve"). Leeds General Infirmary 48:507-510

Terada Y, Shinohara S, Matui N, Ida T (1988): Amphetamineinduced myoglobinuric acute renal failure. Jap J Med 27:305-308

Thornberg SA, Ereshefsky L (1993): Neuroleptic malignant syndrome associated with clozapine monotherapy. Pharmacotherapy 13:510-514

Tsoi WF, Candilish JK, Kua EH (1985): Creatine phosphokinase and schizophrenia in Singapore. Ann Acad Med Singapore 14:84-86

Verheyen A, Viaminckx E, Lauwers F, Van Den Broeck C, Wouters L (1984): Serotonin-induced blood flow changes in the rat hindlegs after unilateral ligation of the femoral artery. Inhibition by the $S_{2}$ receptor antagonist ketanserin. Arch Int Pharmacodyn Ther 270:280-298

Watson JD, Ferguson C, Hinds CJ, Skinner R, Coakley JH (1993): Exertional heat stroke induced by amphetamine analogues. Does dantrolene have a place? Anaesthesia 48:1057-1060

Yuen EC, Mobley WC (1995): Therapeutic applications of neurotrophic factors in disorders of motor neurons and peripheral nerves. Molec Med Today 1:278-286 